Borysenko L. H. Temporal change in pronoun use and its application to cultural psychology: the case of the Russian language in the 20th century. - The significance of psychology in modern society (conference proceedings). - Kherson, Gelvetika, 2017. - P. 10-14 (ISBN 978-966-916-317-2)

(http://molodyvcheny.in.ua/files/conf/psy/18june2017/18june2017.pdf) 
Borysenko L.H.

PhD, ResearchPro Inc. (Kyiv, Ukraine)

\section{TEMPORAL CHANGE IN PRONOUN USE AND ITS APPLICATION TO CULTURAL PSYCHOLOGY: THE CASE OF THE RUSSIAN LANGUAGE IN THE $20^{\text {TH }}$ CENTURY}

Cultural products seem to be very promising for psychological studies. Lamoreaux and Morling [2] postulated that it is because culture represents the context and the person. Markus and Kitayama [3] put the same idea differently: individuals shape cultural products and cultural products shape individuals' views.

Among various cultural products, books show perhaps the most broad view of cultural change, as they mirror the linguistic peculiarities of people living in a certain_time. Culture is passed on through language, and inseparable from language. Thus, it would not be unreasonable to assume that by studying language change it is possible to examine cultural transformations.

Pronouns, which are the focus of the present study, have been linked to such an important dimension for comparing cultures as individualism and collectivism. In collectivistic cultures, people define themselves according to group membership, while people in individualistic cultures focus on personal rather than group preferences [e. g., 6]. First person singular pronouns (i. e. «I», «me», «my» and so on) are associated with individualism, because they refer to the individual self. First person plural pronouns («we», «our», «us» and so on) are linked with collectivism, as they orient attentional focus toward groups. It is believed that second person pronouns («you», «your», «yours» and so on) are also associated with individualism, because they, according to Twenge et al. [7], separate the actor and other.

The study of pronoun use in American books between 1960 and 2008 showed that the use of first person plural pronouns decreased, whereas the use of first person singular pronouns and second person pronouns increased [7]. In eight of nine languages, first-person singular 
pronouns (vs. first-person plural pronouns) become prevalent in the second half of the $20^{\text {th }}$ century, showing U-shaped trends [10]. For nine languages, there was found a significant positive correlation between Hofstede's individualism score [1] and the relative frequency of first person singular pronouns (but not the overall use of pronouns) [9].

The finding that the pronoun use reflects increasing individualism and decreasing collectivism, and the fact that at least some (mainly Western) cultures become more individualistic in recent decades was confirmed by the study of individualistic and collectivistic words. It was found that during the same period of the $20^{\text {th }}$ century, individualistic words and phases increased in use in American books [8].

I studied changes in pronoun use in the Google Books ngram database [4] of Russian books published in 1900-2000. The $20^{\text {th }}$ century represent a highly interesting and dramatic period in Soviet-Russian history. It includes the late Russian Empire, the Soviet era (with such milestones as collectivization, famine, Civil War, Soviet-German War, perestroika), and the growth of capitalism. The study of pronoun use during this period is an important task in understanding personal and cultural changes propelled by major historical events.

The Google Books ngram database contains 490855 Russian books of this period, with more than 55 billion words. There are many pronoun forms in the Russian language. I retrieved the frequency of all personal and possessive pronouns (in total 114 words, including 28 in the old, pre1918 orthography). Because previous studies on Russian pronouns have focused on just four words - «II», «we», «me», «us» $[9,10]$, the main aim of the present work was to use the full pronoun list in order to get the broad picture of pronoun changes.

The results show that between 1900 and 2000 all pronouns decreased in use, except for third person plural pronouns: $-43 \%$ (first person singular), $-41 \%$ (first person plural), $-45 \%$ (second person), $-36 \%$ (third person singular), $11 \%$ (third person plural) (all values are from the linear regression line). But significant fluctuations are observed during this period (Fig. 1), and the curvilinear trend (namely the cubic trend: updown-up) is much stronger than the linear trend. 
With such a comprehensive set of pronouns, it is now possible to estimate quite accurately the percentage of pronouns in the Russian language. It is estimated as $2.7 \%$ (from $2 \%$ in 1976 to $3.7 \%$ in 1922), which is lower than in English, Italian, German and French, but higher than in Hebrew [9]. The relative frequency of first person singular pronouns over first person plural pronouns is 0.093. Uz [9] and $\mathrm{Yu}$ at al. [10] reported fairly similar values by using just four pronouns. In other languages studied to date, the relative frequency of first person singular pronouns over first person plural pronouns varies from ca 0.3 to $-0.2[9 ; 10]$.

The correlation between first person singular pronouns and first person plural pronouns, which perhaps most clearly associated with individualism-collectivism, was weak and marginally significant $(\mathrm{r}=0.20 ; \mathrm{P}=0.05)$. Interestingly, in American English it was quite profound $(\mathrm{r}=0.57 ; \mathrm{P}<0.0001)$. Contrary to what has been reported for 1901-2009 [5], the correlation between Russian individualistic and collectivistic words was statistically insignificant $(\mathrm{r}=0.07 ; \mathrm{P}=0.46)$, but marginally significant and weak for English (American English) individualistic and collectivistic words from Twenge et al. [8] ( $\mathrm{r}=0.21$; $\mathrm{P}=0.04)$.

Despite a century-long decrease, the period from 1960 is characterized by an increase in use for all pronouns: $82 \%$ (first person singular), 18\% (first person plural), 60\% (second person), 29\% (third person singular), $2 \%$ (third person plural) (all values are from the linear regression line). For American English (1960-2008), Twenge et al. [7] reported an increase in use for first person singular and second person pronouns, and a decrease for the other pronouns. The results on the Russian language are in agreement with those findings and also indicate a trend toward greater individualism, although the changes seem to be not so profound, and first person plural pronouns even moderately increased in use. To make this conclusion more evident, I calculated the difference between the relative frequencies of first person singular and first person plural pronouns. The increase of this difference was $111 \%$ for American English, and considerably higher for the Russian language: 4 021\% (values are from the linear regression line). 


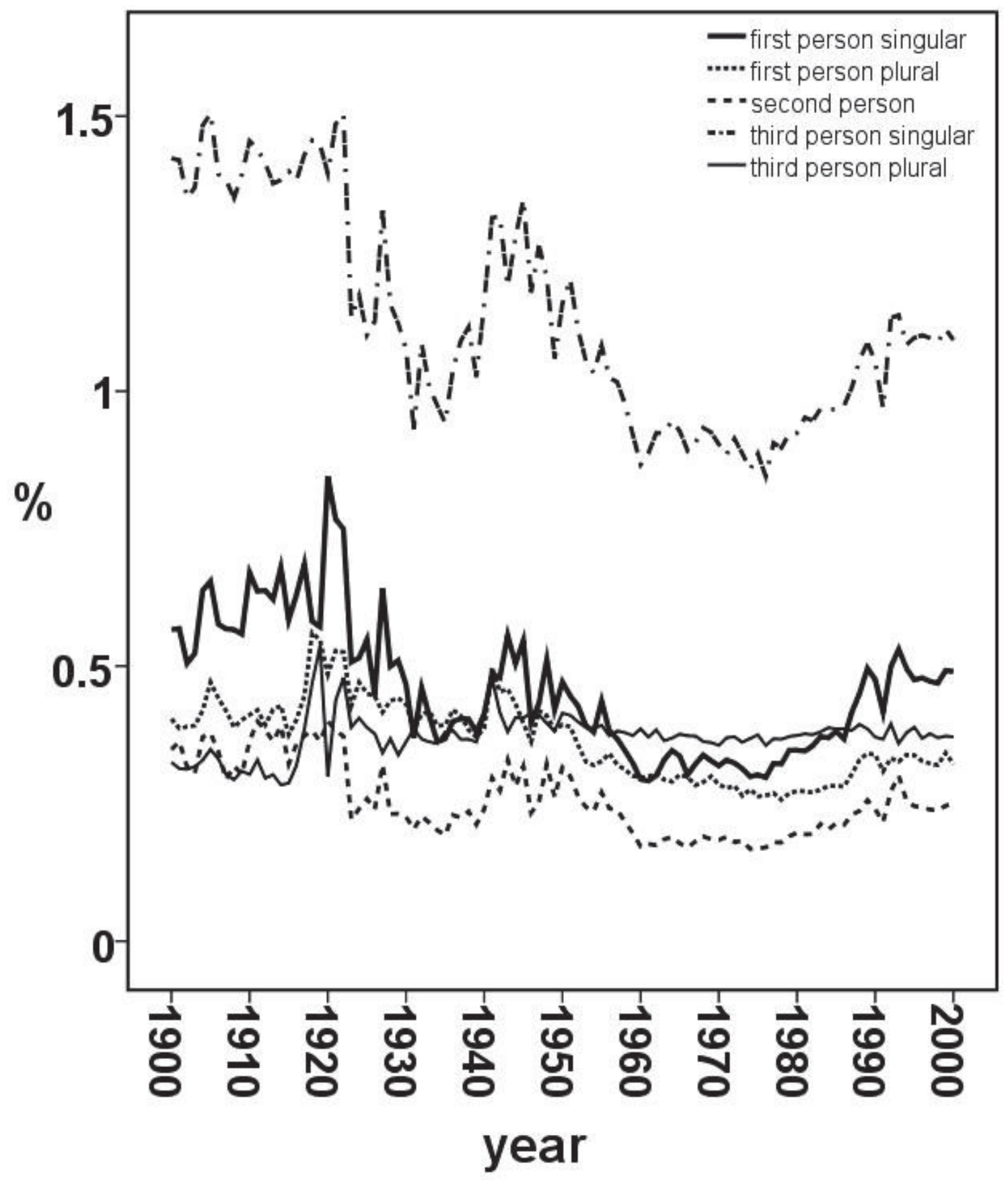

Fig. 1. Changes in pronoun use in Russian books, 1900-2000

The last stage of the present exploration was a change point analysis. This is a useful and interesting technique widely and increasingly used in many research fields, but still rare in linguistic studies. The obtained statistically significant change points nicely coincide with the major events of Russian-Soviet history during the $20^{\text {th }}$ century (e.g., the Bolshevik Revolution, Soviet-German War, perestroika). 
The present report is just a brief summary of the main findings. Details of this work will be published elsewhere.

\section{References:}

1. Hofstede G. Culture's consequences: comparing values, behaviors, institutions and organizations across nations / G. Hofstede. - Sage Publications, 2001. $-622 \mathrm{p}$.

2. Lamoreaux M. Outside the head and outside individualismcollectivism: further meta-analyses of cultural products / M. Lamoreaux, B. Morling // Journal of Cross-Cultural Psychology. - 2012. - Vol. 43, No 2. P. 299-327.

3. Markus H. R. Cultures and selves: a cycle of mutual constitution / H. R. Markus, S. Kitayama // Perspectives on Psychological Science. 2010. - Vol 5, No 4. - P. 420-430.

4. Michel J. B. Quantitative analysis of culture using millions of digitized books / J. B. Michel, Y. K. Shen, A. P. Aiden et al. // Science. - 2011. Vol .331. - P. 176-182.

5. Skrebyte A. Temporal relationships between individualism-collectivism and the economy in Soviet Russia: a word frequency analysis using the Google Ngrams corpus / A. Skrebyte, P. Garnett, J. R. Kendal // Journal of CrossCultural Psychology. - 2016. - Vol. 47, No 9. - P. 1217-1235.

6. Triandis H. C. Individualism and collectivism / H. C. Triandis. Westview Press, 1995. - 284 p.

7. Twenge J. M. Changes in pronoun use in American books and the rise of individualism, 1960-2008 / J. M. Twenge, W. K. Campbell, B. Gentile // Journal of Cross-Cultural Psychology. - 2012a. - Vol. 44, No. 3. - P. 406-415.

8. Twenge J. M. Increases in individualistic words and phrases in American books, 1960-2008 / J. M. Twenge, W. K. Campbell, B. Gentile // PloS One. - 2012b. - Vol. 7, No. 7. - P. e40181.

9. Uz I. Individualism and first person pronoun use in written texts across languages / I. Uz // Journal of Cross-Cultural Psychology. - 2014. - Vol. 45, No 10. - P. 1671-1678.

10. Yu F. Cultural value shifting in pronoun use / F. Yu, T. Peng, K. Peng et al. // Journal of Cross-Cultural Psychology. - 2016. - Vol. 47, No 2. P. 310-316. 